\title{
RESEARCH
}

\section{Restrictive access to clopidogrel and mortality following coronary stent implantation}

\author{
Odile Sheehy MSc, Jacques LeLorier MD PhD, Stéphane Rinfret MD MSc
}

$\infty$

See related article page 425

\section{ABSTRACT}

Background: In Canada, access to clopidogrel is restricted by most provincial drug insurance plans in order to contain costs. Until April 2007, the Régie de l'assurance maladie du Québec (RAMQ) Prescription Drug Insurance Plan reviewed special access forms before approving reimbursement for clopidogrel prescriptions. We investigated the impact of this restrictive process on patient's filling of prescriptions and on all-cause mortality following coronary stenting.

Methods: We analyzed prescriptions filled and all-cause mortality in the year following a percutaneous coronary intervention among patients who underwent stent implantation between January 2000 and September 2004. We obtained administrative data from the RAMQ databases. We included patients who filled at least 1 prescription for a nonrestricted cardiovascular drug after hospital discharge. We used Cox proportional models to compare mortality rates as a function of delayed or absent outpatient clopidogrel therapy.

Results: Of 13663 patients, 1571 (11.5\%) did not fill any clopidogrel prescription despite filling at least 1 nonrestricted cardiovascular drug prescription after a percutaneous coronary intervention, and 1174 (8.6\%) patients filled their clopidogrel prescription with a delay of at least 1 day (median delay 5 days) after filling the nonrestricted cardiovascular drug prescription. After controlling for pertinent covariables, not filling a clopidogrel prescription (hazard ratio [HR] 1.70, 95\% confidence interval [Cl] 1.35-2.15) and filling with a delay (HR 1.34, 95\% Cl 1.01-1.80) were associated with a significant increase in all-cause mortality.

Interpretation: Restricted access to clopidogrel was associated with about $20 \%$ of patients either not receiving clopidogrel or receiving therapy after a delay. Delay or absence of clopidogrel therapy increased the risk of all-cause mortality after percutaneous coronary intervention with stenting.

Une version française de ce résumé est disponible à l'adresse www.cmaj.ca/cgi/content/full/178/4/4I3/DCI

$C M A J$ 2008;178(4):413-20

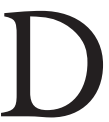
espite the positive dose-response relation between the level of health insurance coverage for preventive care and the recommended preventive services received, an increasing number of private and public drug plans are using preferred drug lists or preauthorization programs or both for cost-containment purposes. ${ }^{1}$ The use of these lists may negatively impact health care outcomes. ${ }^{2}$ In the Régie de l'assurance maladie du Québec (RAMQ) Prescription Drug Insurance Plan, 158 drugs are reimbursed through a prior authorization process. ${ }^{3}$ One of these restricted drugs is clopidogrel, a thienopyridine antiplatelet agent that reduces the risk of thrombosis following coronary stenting, a complication that often results in death. ${ }^{4}$ The benefits of thienopyridine therapy in conjunction with acetylsalicylic acid for this indication are based on solid evidence..$^{5-9}$ Furthermore, clopidogrel reduces atherothrombotic and other major clinical events in the year following percutaneous coronary intervention with stent implantation. ${ }^{10,11}$ To be effective, timely antiplatelet therapy is critical. ${ }^{12}$

Before April 2007, physicians had to complete and fax a special authorization form to RAMQ for approval of clopidogrel therapy. In this pharmacoepidemiologic study, we evaluated the effects of this authorization process on clopidogrel prescription filling and all-cause mortality among patients who underwent coronary stenting.

\section{Methods}

\section{Data sources}

We combined information from 3 RAMQ databases. Information on each outpatient drug claim was obtained from the drug claims database. This database has been validated ${ }^{13,14}$ and has been used in other studies. ${ }^{15-18}$ From the medical services database we obtained data on physician visits; International Classification of Diseases (ninth revision, clinical modification [ICD-9-CM]) diagnosis codes; procedures performed $;{ }^{19}$ the date of each visit; and information about the site of service. We obtained patient sex, date of birth, type of coverage and the date of death for deceased patients from the demographics database. Each patient's socioeconomic status was assumed based on their maximum monthly copayment, which ranged from $\$ \circ$ (patients on social security with severe employment constraints) to $\$ 73.42$ based on family income.

From the Pharmacoeconomics and Pharmacoepidemiology Unit (Sheehy, LeLorier, Rinfret), Centre Hospitalier de I'Université de Montréal Research Centre, and the Division of Cardiology (Rinfret), Department of Medicine, Centre Hospitalier de l'Université de Montréal, Université de Montréal, Montréal, Que. 
Patient records were linked across the databases by use of unique health insurance numbers, which are encrypted to protect confidentiality.

\section{Patient population}

RAMQ provided a random sample of $39 \%$ (to further protect patient confidentiality) of the 47362 patients who underwent a percutaneous coronary intervention with stenting between Jan. I, 2000, and Sept. 30, 2004. To be included in the final analysis, patients had to have filled at least I prescription for a nonrestricted cardiovascular drug (e.g., acetylsalicylic acid, warfarin, oral antidiabetic, antihypertensive or lipidmodifying drug) during the year following the percutaneous coronary intervention. We excluded patients who, in the year before the procedure, had filled a prescription for clopidogrel or did not have RAMQ drug-plan coverage. We also excluded patients whose RAMQ drug coverage ended within the month after the percutaneous coronary intervention.

\section{Primary outcome}

Considering the life-threatening consequences of stent thrombosis, ${ }^{4,5}$ the long-term favourable effect of clopidogrel on cardiovascular outcomes ${ }^{9-11}$ and the lack of incentives for physicians to include diagnostic information on RAMQ administrative claims (and the potential for misclassification), we used all-cause mortality as our primary outcome.

\section{Variables}

To measure the impact of the special authorization process on timely patient access to clopidogrel, we hypothesized that if there was no special authorization process, patients would fill their prescriptions for clopidogrel and nonrestricted cardiovascular drugs at the same time. Thus, we assumed that whenever a claim for a nonrestricted cardiovascular drug was claimed first followed by a later claim for clopidogrel, the delay between the 2 claims was because of the authorization process. Furthermore, if clopidogrel was not claimed after the nonrestricted cardiovascular drug, we assumed that this was also because of the authorization process.

We divided the patients into 3 groups; those with no delay between their first nonrestricted cardiovascular drug claim and first clopidogrel claim, those with at least a I-day delay between claims, and those who did not fill a clopidogrel prescription after stenting despite having a nonrestricted cardiovascular drug claim. We collected patient's data from the RAMQ databases during the period following discharge up to I year or until they became ineligible for the RAMQ Prescription Drug Insurance Plan coverage (at which point they were excluded from subsequent follow-up) or until they died, whichever came first.

\section{Statistical analysis}

The index date was defined as the date of discharge from hospital following a percutaneous coronary intervention. The date on which the first nonrestricted cardiovascular drug prescription was filled was identified for each patient. We calculated the difference in days between the date of discharge and the date on which the first nonrestricted cardiovascular drug pre- scription was filled. For patients who filled a clopidogrel prescription, we calculated the number of days between when the patient's first prescription for a nonrestricted cardiovascular drug was filled and when the clopidogrel prescription was filled. To assess comorbidity, we calculated a chronic disease score based on drug use in the year before the percutaneous coronary intervention. ${ }^{20}$ We determined exposure to clopidogrel by calculating the percentage of days the patient received clopidogrel therapy in the I year following discharge. This method also accounted for adherence and duration of treatment. ${ }^{21-23}$ We also assessed adherence to nonrestricted cardiovascular drugs by calculating the percentage of days on the same drug class during the follow-up period. Discrete data are presented as percentage, and continuous data are presented as mean (standard deviation $[S D]$ ) and median (25th-75th percentile) when nonnormally distributed. Because of the large sample size, we did not compare baseline data.

We used a cohort study design for our analyses. We generated unadjusted Kaplan-Meier curves for the 3 groups and compared survival using a log-rank test. We used a Cox proportional hazards model to compare the risk of mortality as a function of delayed or absent clopidogrel therapy compared with nondelayed clopidogrel therapy, after adjustment for important measured covariables by use of a stepwise selection process. A significance level of 0.25 was used to allow a variable into the model and o.Io was used to allow a variable to stay in the model. Using the same modelling methods, we performed a sensitivity analysis by mortality among patients with delayed or no clopidogrel therapy and those who received clopidogrel with no delay. Adjusted associations were measured with hazard ratios (HR) and corresponding 95\% confidence intervals (CI). A HR greater than $\mathrm{I}$ indicates an increase in the risk of death. Finally, we assessed the impact of delayed or absent clopidogrel therapy by comparing data from patients who underwent a percutaneous coronary intervention before December 2002 (no drug-eluting stents available) to those who underwent percutaneous coronary intervention after December 2002 (drug-eluting stents used more often).

\section{Results}

\section{Study population}

We identified I8 47I patients who underwent coronary stenting between January 2000 and September 2004. Of these, I3 663 patients met our selection criteria (Figure I).

\section{Clopidogrel use during follow-up}

For 2745 (20.1\%) patients, there was a delay to initiate or an absence of outpatient clopidogrel therapy. A total of I $_{5} 65$ (II. $5 \%$ ) patients did not fill a clopidogrel prescription after stenting. For II 80 (8.6\%) patients, the clopidogrel prescription was filled with a delay of at least I day after the nonrestricted cardiovascular drug prescription was filled. Among these patients, the median delay to fill the clopidogrel prescription was 5 days (25th-75th percentile 2-I9 days). Sixty-one percent of patients filled their clopidogrel prescription within 7 days, $\mathrm{II} \%$ filled their prescription within $8-\mathrm{I} 4$ days and $28 \%$ filled their prescription after more than 14 days. The remaining Io 918 
(79.9\%) patients filled their prescriptions for clopidogrel and nonrestricted cardiovascular drugs at the same time.

\section{Demographics and use of resources and drugs}

The demographic characteristics and initial hospital admission data for patients of the 3 groups (filled a clopidogrel prescription without a delay, filled a clopidogrel prescription with a delay, did not fill a clopidogrel prescription) are shown in Table I. Most patients (63\%) were male, and the median age was 70 years. This was similar across the 3 patient groups. The majority of the patients were in the highest monthly copayment stratum. The chronic disease scores were similar among the 3 groups. We observed a longer hospital stay among patients who did not fill any clopidogrel prescriptions after discharge.

The rates of health care resource use in the year before the percutaneous coronary intervention are presented in Table 2 and were similar among the 3 groups. Table 3 presents information on drug use. The delay in filling prescriptions for nonrestricted cardiovascular drugs after discharge was similar among the groups, although the delay was slightly longer among patients who never filled a clopidogrel prescription. Overall, $75 \%$ of patients filled their prescription for nonrestricted cardiovascular drugs within I day of discharge. Compared with patients who either had delayed or no outpatient clopidogrel therapy, patients who had no delay were prescribed clopidogrel and nonrestricted cardiovascular drugs more often by the cardiologist who performed the percutaneous intervention or by another cardiologist. Exposure to clopidogrel during the follow-up period among patients who filled their clopidogrel prescription was similar among the 3 groups. Drug adherence to nonrestricted cardiovascular drug therapy was high $(>75 \%)$ in all 3 groups.

\section{Univariable analysis}

At I-year follow-up, 476 (3.5\%) patients had died. The crude difference in mortality between the 3 groups was statistically significant: $2.9 \%$ for those without a delay, $4.5 \%$ for those with a delay and $6.9 \%$ for those who did not receive clopidogrel (log-rank test: $p<0.00 I$ ) (Figure 2).

\section{Multivariable adjusted analyses}

After we adjusted for the potential confounding covariables listed in Table $\mathrm{I}$, Table 2 and Table 3, we found that patients who filled a clopidogrel prescription with a delay of at least I day after filling a nonrestricted cardiovascular drug prescription were at a higher risk of mor- tality than patients without a delay (adjusted HR I.35, 95\% CI I.OI-I.80). Patients who did not fill a clopidogrel prescription had a greater adjusted risk of mortality (adjusted HR I.70, 95\% CI I.35-2.15) (Figure 3, Appendix I, available online at www.cmaj.ca/cgi/content/full/178/4/4I3/DC2).

In the sensitivity analysis (patients with delayed or no clopidogrel therapy were grouped), the effect of suboptimal clopidogrel therapy after a percutaneous coronary intervention was associated with a $55 \%$ increase in the risk of death (adjusted HR I.55, 95\% CI I.27-I.89).

Finally, restricting our analysis to include only patients who received a bare-metal stent (prior to December 2002) did not affect the direction of our findings (data not shown).

\section{Interpretation}

We examined the impact of restrictive access to clopidogrel antiplatelet therapy on prescription filling and all-cause mortality after percutaneous coronary intervention with stenting. In our

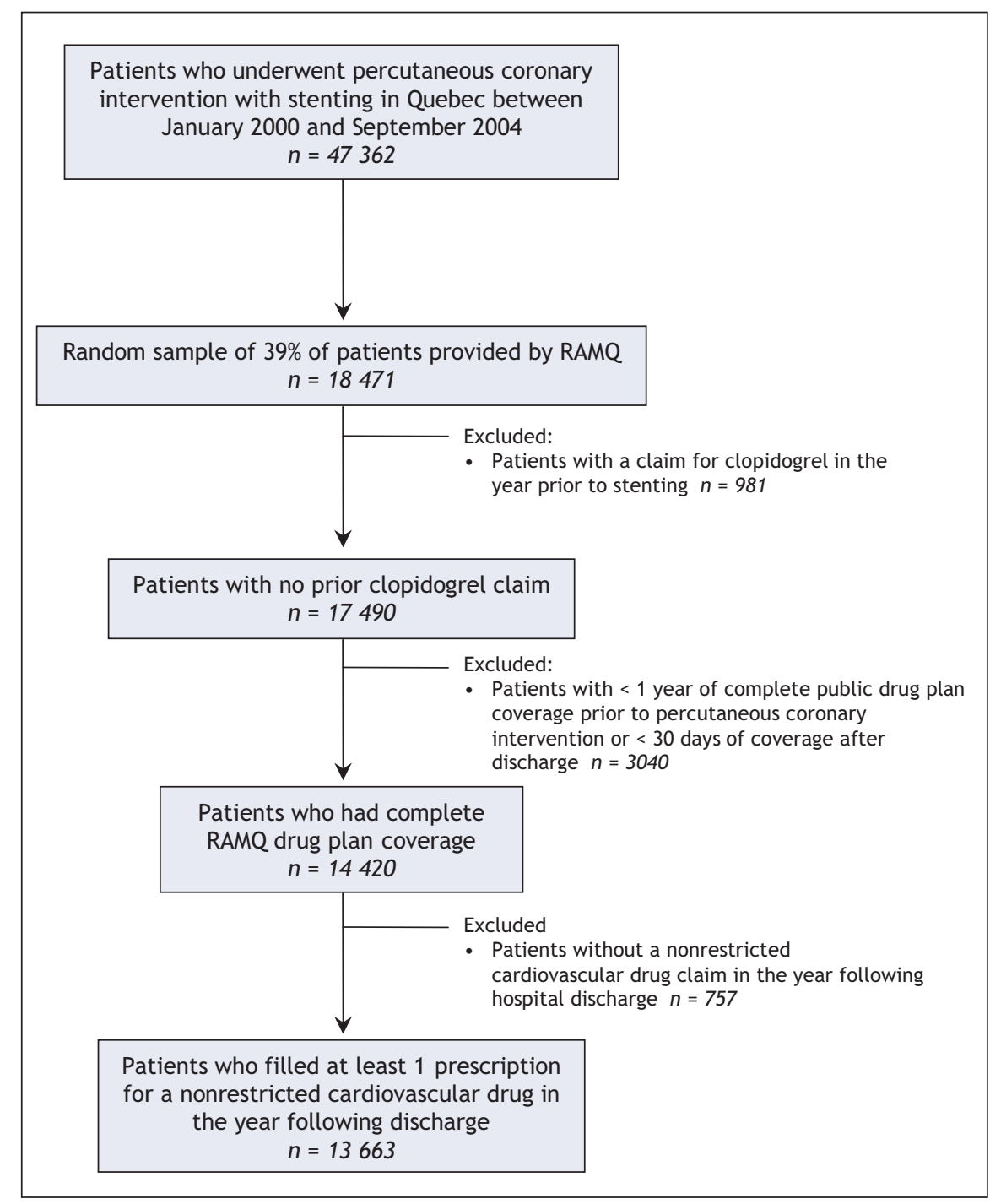

Figure 1: Selection of the study population. Note: RAMQ = Régie de l'assurance maladie du Québec. 
study, about $20 \%$ of patients who were discharged after stenting had either delayed $(8.6 \%)$ or no (II. $5 \%$ ) clopidogrel therapy, despite filling a prescription for a nonrestricted cardiovascular drug in the I-year period after the intervention. Delaying clopidogrel therapy by at least I day increased the risk of allcause mortality by $34 \%$, and the absence of outpatient clopidogrel therapy was associated with a $70 \%$ increase in the risk of mortality, after adjustment for covariables. From a populationhealth perspective, the adjusted $55 \%$ increase in mortality risk with delayed or absent clopidogrel therapy corresponds to an attributable risk of death of $\mathrm{I} .6 \%(2.9 \% \times[\mathrm{I} .55-\mathrm{I}])$. In our study, $20.1 \%$ of patients had delayed or absent clopidogrel therapy. This results in a population attributable risk of $0.32 \%$, which is the proportion of patients who died likely because of the restrictive approval process. Each year in Quebec, about I5 000 patients undergo stent implantation; thus, we estimate that about 50 deaths could have been avoided each year if access to clopidogrel therapy would have been optimized earlier.
Although others have found that premature discontinuation of clopidogrel is common early after implantation of a drug-eluting stent and is associated with an increased risk of mortality, ${ }^{24}$ our study examined the adverse effects of delayed or absent outpatient clopidogrel therapy on patient outcomes after the implantation of any type of stent. Our conclusions about the adverse role of the administrative process are in agreement with another study in Alberta that examined the effects of 2 approval processes for clopidogrel (prior authorization similar to that in Quebec up to April 2007 v. authorized prescriber, in place since March 2002) by the Alberta Blue Cross in a small cohort of II2 patients who underwent coronary stenting. ${ }^{25}$ Patients treated during the authorizedprescriber period were more likely to fill their prescription on the day of discharge compared with patients for whom prior authorization was required $(54 \% \mathrm{v} \cdot 3 \mathrm{I} \%) .{ }^{25}$ At the time of data collection, up to 48 hours were required for authorization to reach the pharmacy. Therefore, given that most patients were

Table 1: Demographic characteristics and hospital data for 13663 patients who underwent percutaneous coronary intervention with stenting between January 2000 and September 2004

\begin{tabular}{|c|c|c|c|}
\hline Characteristic & $\begin{array}{l}\text { Did not fill clopidogrel prescription; } \\
\qquad \begin{array}{l}\% \text { of patients* } \\
n=1565\end{array}\end{array}$ & \multicolumn{2}{|c|}{ Filled clopidogrel prescription; \% of patients* } \\
\hline Male & 62 & 64 & 63 \\
\hline \multicolumn{4}{|l|}{ Age, yr } \\
\hline$<64$ & 28.0 & 34.3 & 32.5 \\
\hline$\geq 74$ & 38.7 & 37.5 & 35.2 \\
\hline Median (25th-75th percentile), yr & $70(62-76)$ & $69(59-75)$ & $69(60-75)$ \\
\hline Mean (SD), yr & $68.2(11.4)$ & $67.1(11.6)$ & $67.1(11.1)$ \\
\hline \multicolumn{4}{|c|}{ Maximum monthly copayment, † Can\$ } \\
\hline 0 & 3.7 & 7.9 & 5.9 \\
\hline \multicolumn{4}{|l|}{ Chronic disease score, $¥$} \\
\hline$<2$ & 74.4 & 72.5 & 75.0 \\
\hline $3-6$ & 20.7 & 20.8 & 20.6 \\
\hline$\geq 7$ & 4.9 & 6.8 & 4.3 \\
\hline Median (25th-75th percentile) & $5(1-7)$ & $5(1-7)$ & $4(1-7)$ \\
\hline Mean (SD) & $4.6(3.8)$ & $4.8(3.9)$ & $4.5(3.6)$ \\
\hline \multicolumn{4}{|l|}{$\begin{array}{l}\text { Length of hospital stay for coronary } \\
\text { stent placement, } d\end{array}$} \\
\hline$<5$ & 22.6 & 26.2 & 31.1 \\
\hline
\end{tabular}

Note: SD = standard deviation

*Unless otherwise specified.

†Maximum monthly copayment to the Régie de l'Assurance Maladie du Québec Prescription Drug Insurance Plan.

$\ddagger$ Scores derived from Von Korff et al. ${ }^{19} \mathrm{~A}$ higher score indicates increased disease. 
discharged the day following the intervention and that they filled their nonrestricted cardiovascular drug prescriptions on the day of discharge or the next day, it is likely that some patients could only obtain their clopidogrel by paying the full cost of the prescription (about Can\$92), a cost that many pa- tients could not afford. We believe that the large number of patients who did not request a clopidogrel prescription later on can be attributed to the fact that clopidogrel was not dispensed the first time with the patient's other medications. Therefore, applying a preauthorization process for clopidogrel

Table 2: Health care resources use in the year before percutaneous coronary intervention with stenting for 13663 patients

\begin{tabular}{|c|c|c|c|}
\hline Resource & $\begin{array}{l}\text { Did not fill clopidogrel } \\
\text { prescription } \\
n=1565\end{array}$ & \multicolumn{2}{|c|}{ Filled clopidogrel prescription } \\
\hline \multicolumn{4}{|l|}{ Family physicians, no. of visits } \\
\hline Median (25th-75th percentile) & $4(1-7)$ & $4(1-7)$ & $4(1-6)$ \\
\hline Mean (SD) & $4.6(4.6)$ & $4.8(4.5)$ & $4.5(4.3)$ \\
\hline Median (25th-75th percentile) & $0(0-2)$ & $0(0-2)$ & $0(0-2)$ \\
\hline Mean (SD) & $1.1(1.9)$ & $2.0(4.4)$ & $1.1(1.8)$ \\
\hline \multicolumn{4}{|l|}{ Other specialists, no. of visits } \\
\hline Median (25th-75th percentile) & $3(1-7)$ & $3(1-7)$ & $3(1-6)$ \\
\hline Mean (SD) & $6.2(15.9)$ & $6.3(15.2)$ & $5.6(12.8)$ \\
\hline \multicolumn{4}{|l|}{ No. of emergency room visits } \\
\hline Median (25-75 percentile) & $1(1-2)$ & $1(1-2)$ & $1(1-2)$ \\
\hline Mean (SD) & $1.5(1.5)$ & $1.5(.4)$ & $1.4(1.4)$ \\
\hline
\end{tabular}

Note: $\mathrm{SD}=$ standard deviation.

Table 3: Prescribing and use of clopidogrel and nonrestricted cardiovascular drugs for 13663 patients who underwent percutaneous coronary intervention with stenting between January 2000 and December 2004

Delay in filling first prescription for a nonrestricted cardiovascular drug after hospital discharge, $d$

Median (25th-75th percentile)

Mean (SD)

First nonrestricted cardiovascular drug claim filled within 24 hours of discharge, $\%$ of patients

Clopidogrel exposure during follow-up, \% of days with medication available (SD)

Clopidogrel or nonrestricted cardiovascular drug prescribed by a cardiologist, \%

Clopidogrel or nonrestricted cardiovascular drug prescribed by the cardiologist who performed the percutaneous coronary intervention, $\%$ of patients

Prescription for acetylsalicylic acid filled in the 1-year period after discharge (at least $1 \mathrm{claim}$ ), \% of patients

Adherence to nonrestricted cardiovascular drug therapy, \% of days with medication available

Median (25th-75th percentile)
Mean (SD)
Did not fill clopidogrel Filled clopidogrel prescription prescription With delay Without delay

$n=1565 \quad n=1180 \quad n=10918$

Note: $\mathrm{SD}=$ standard deviation . 


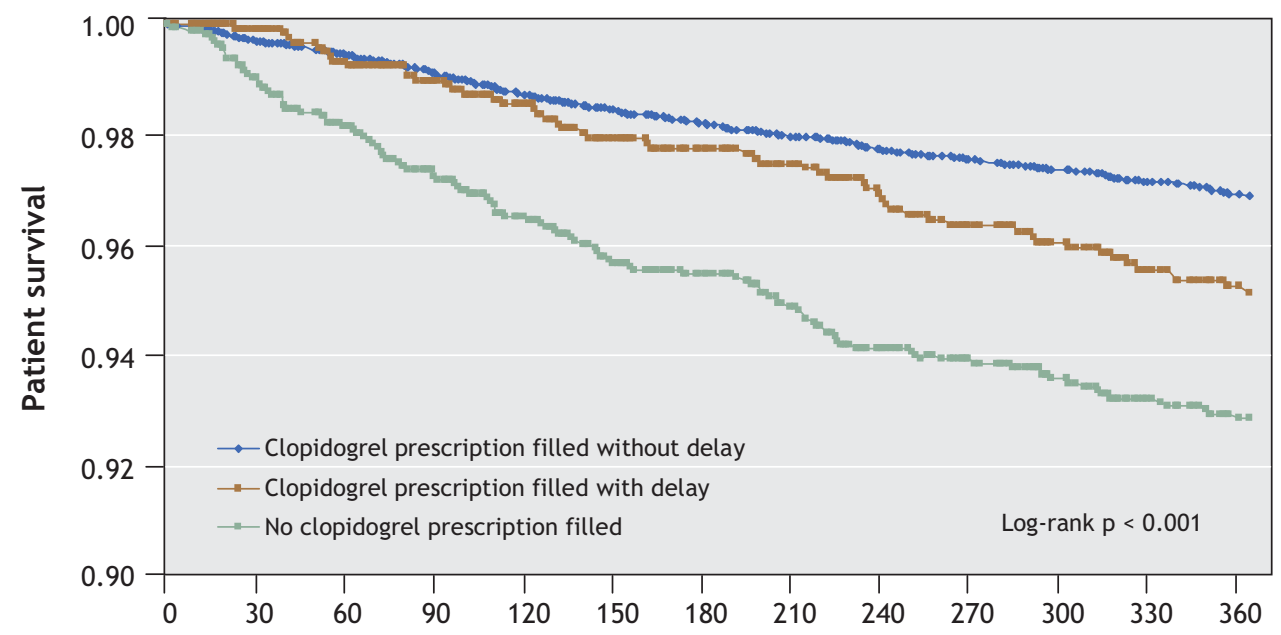

Survival after percutaneous coronary intervention, $d$

No. at risk*

Clopidogrel without delay 10918

Clopidogrel with delay $\quad 1180$

No clopidogrel 1565

No. of deaths

Clopidogrel without delay

Clopidogrel with delay

No clopidogrel

Total no. of deaths

Clopidogrel without delay

Clopidogrel with delay

No clopidogrel

10785
1180
1565

95
12
41

95
12
41

10785

180

95

12

41

95

12

41

10018
1082
1440

97
14
29

192
26
70

9255

1004

1364

$\begin{array}{rr}63 & 60 \\ 15 & 12 \\ 23 & 15 \\ 255 & 315 \\ 41 & 53 \\ 93 & 108\end{array}$

Figure 2: Survival curves for patients who underwent percutaneous coronary intervention with stenting between January 2000 and December 2004. Note: $\mathrm{Cl}=$ confidence interval. *No. at risk excludes patients who became ineligible for drug coverage during the previous period of follow-up.

irrespective of the clinical indication was clearly inadequate because these patients had no other drug alternative after stenting. In our study, the health consequences of delaying or not filling clopidogrel prescriptions were catastrophic. In 2003 , the preauthorization for clopidogrel was recognized as a potential risk by the Ontario Drug Benefit program when it facilitated access for proven indications, such as after receiving a stent. Therefore, based on our findings in Quebec, hundreds of lives in Ontario have likely been saved by this decision.

Our study, however, has several limitations. First, the cohort of patients was from an administrative database, which does not contain information about many important risk factors. As a result, we cannot exclude the possibility of residual confounding in the association between suboptimal filling of clopidogrel prescriptions and mortality. However, the prevalence of unmeasured clinical factors was unlikely to be different across the study groups. It is also improbable that such factors account for the important increase in mortality among patients without outpatient clopidogrel therapy. Second, the groups were defined by the authors rather than randomized, which gives rise to the potential for immortal time bias, which refers to the artificially improved survival among patients who fill prescriptions, because it is impossible for them to have died before filling their pre- scription. ${ }^{26}$ We found that patients who never filled their clopidogrel prescription filled their prescription for nonrestricted cardiovascular drugs later than patients who filled the 2 prescriptions at the same time. Immortal time bias should therefore have protected the patients who never filled a clopidogrel prescription; however, we observed a strong association between no clopidogrel therapy and mortality. Patients with delayed clopidogrel therapy filled their nonrestricted cardiovascular drug prescriptions slightly earlier than patients with no delay. Given that patients who filled the 2 prescriptions at the same time did so slightly later, this potentially introduced immortal time bias. However, the bias was also protective for patients in the delayed clopidogrel therapy group up to the time that they filled their clopidogrel prescription. Nevertheless, we observed a $34 \%$ increased risk of mortality. Although immortal time bias could have played a role in a comparison between delayed clopidogrel therapy and no therapy, we did not analyze this comparison. Moreover, when we pooled the patients with delayed or no therapy, we still observed a $55 \%$ increase in mortality with suboptimal clopidogrel use. Third, it is possible that the suboptimal use of clopidogrel was because of reasons other than the authorization process, such as patient- or physicianrelated factors. However, lack of adherence is unlikely to explain 


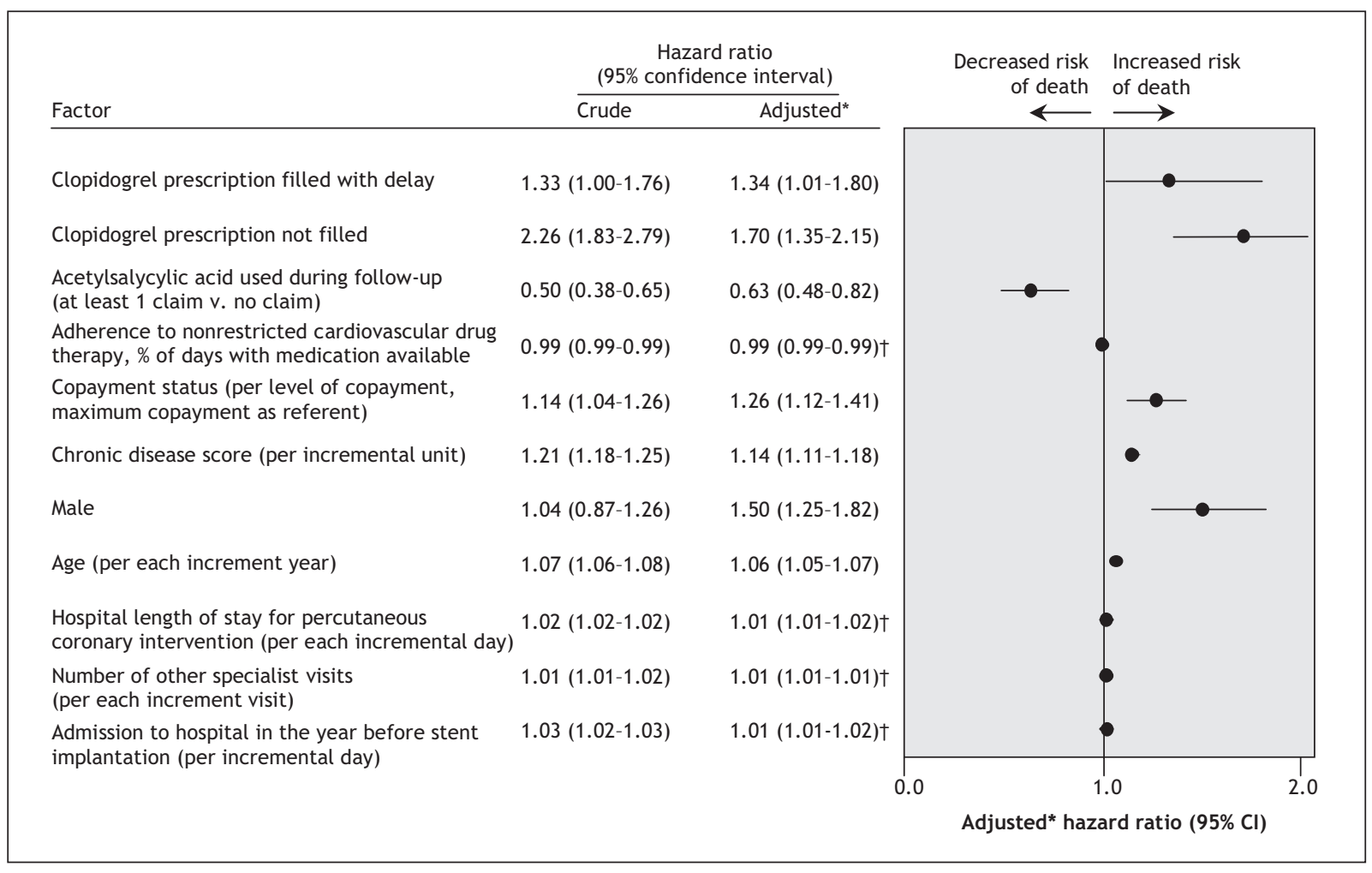

Figure 3: Crude and adjusted risk of death among patients who underwent stent implantation between January 2000 and September 2004. *Adjusted (forward stepwise selection) for sex; age; Régie de l'assurance maladie du Québec drug plan maximum monthly copayment; chronic disease score; length of stay in hospital for stent implantation; no. of days in hospital in the year before stent implantation; no. of visits to emergency room, family physician, cardiologist, other specialists in the year before stent implantation; concomitant acetylsalicylic acid use; compliance to nonrestrictive cardiovascular drugs and year of stent implantation. †Despite appearing to be nonsignificant, the adjusted hazard ratios for adherence to nonrestricted cardiovascular drug therapy, hospital length of stay, number of other specialist visits and admission to hospital in the year before stent implantation were each significant $(95 \% \mathrm{Cl}$ excluding 1$)$.

the underuse of clopidogrel because all patients included in our analysis adhered to their nonrestricted cardiovascular drug. Given the well-known benefits of clopidogrel therapy after stenting, we think that it is improbable that patients did not receive prescriptions for clopidogrel at discharge. Fourth, the survival curves did not show a difference in mortality between delayed clopidogrel therapy and no therapy within the first 4 months of follow-up. This might be surprising at first glance. However, we can reasonably assume that the patients included in our study received clopidogrel while in hospital. They all survived to the point of filling a nonrestricted cardiovascular drug prescription, which is another potential reason for a later separation of the curves. Some immortal time bias could have been in favour of the group who filled their clopidogrel prescriptions with a delay; however, if such bias was present, it must have been short, given that the delay to fill clopidogrel prescriptions was much shorter than 4 months. Also, we only measured mortality; thus, it is possible that nonfatal events occurred earlier, which resulted in mortality later. Fifth, the type of stent used (bare-metal stent $v$. drug-eluting stent) is unavailable from the RAMQ database. Finally, it is also not possible to know from the RAMQ database if and when the authorization was sent to the pharmacy. Therefore, the association between the underuse of clopidogrel and the approval process can only be suspected based on our study assumptions.

In response to increasing drug-related costs, health care payors in Canada and other industrialized countries are applying restrictive measures, such as special authorization processes. Our findings indicate that the potential adverse effects on major public health outcomes should be evaluated before implementing any procedure that limits access to medications that are important for secondary prevention, especially when the medications are life saving.

This article has been peer reviewed.

Competing interests: Bristol-Myers Squibb and Sanofi-Aventis provided financial support for the study. No competing interests were declared for Odile Sheehy. Jacques LeLorier and Stéphane Rinfret have received consulting fees from Bristol-Myers Squibb and Sanofi-Aventis.

Contributors: All of the authors contributed to the conception and design of the study, acquisition and interpretation of the data and drafting and revising the manuscript. All of the authors have approved the final version for publication.

Acknowledgements: The authors thank Anita Massicotte, Laura McKeeman and Anthony Pierce for their assistance with the preparation of the manuscript and Dr. Patrizia Santagata for her useful comments. Stéphane Rinfret is a junior clinician scientist of the Fonds de la recherche en santé du Québec. 


\section{REFERENCES}

I. Faulkner LA, Schauffler HH. The effect of health insurance coverage on the appropriate use of recommended clinical preventive services. Am J Prev Med i997;13:453-8.

2. Burroughs VJ. Why worry about restricting access to medicines in Medicaid? Am J Manag Care. 2005;II Spec No:SP4-5.

3. Régie de l'assurance maladie du Quebec: service de l'information aux professionnels. Liste de médicaments. I $3^{\text {th }}$ edition. Quebec: Régie de l'assurance maladie; 2006. Available: www.ramq.gouv.qc.ca/fr/professionnels/listmed/lm_tdmf_ajour .shtml\#ahfs (accessed 2008 Jan II).

4. Cutlip DE, Baim DS, Ho KK, et al. Stent thrombosis in the modern era: a pooled analysis of multicenter coronary stent clinical trials. Circulation 2001;103:1967-7I.

5. Bertrand ME, Legrand V, Boland J, et al. Randomized multicenter comparison of conventional anticoagulation versus antiplatelet therapy in unplanned and elective coronary stenting. The full anticoagulation versus aspirin and ticlopidine (fantastic) study. Circulation 1998;98:1597-603.

6. Bertrand ME, Rupprecht HJ, Urban P, et al. Double-blind study of the safety of clopidogrel with and without a loading dose in combination with aspirin compared with ticlopidine in combination with aspirin after coronary stenting: the clopidogrel aspirin stent international cooperative study (CLASSICS). Circulation 2000;102:624-9.

7. Leon MB, Baim DS, Popma JJ, et al. A clinical trial comparing three antithrombotic-drug regimens after coronary-artery stenting. Stent Anticoagulation Restenosis Study Investigators. N Engl J Med I998;339:I665-7I.

8. Schomig A, Neumann FJ, Kastrati A, et al. A randomized comparison of antiplatelet and anticoagulant therapy after the placement of coronary-artery stents. N Engl J Med i996;334:1084-9.

9. Urban P, Macaya C, Rupprecht HJ, et al. Randomized evaluation of anticoagulation versus antiplatelet therapy after coronary stent implantation in high-risk patients: the multicenter aspirin and ticlopidine trial after intracoronary stenting (MATTIS). Circulation I998;98:2126-32.

Io. Mehta SR, Yusuf S, Peters RJ, et al. Effects of pretreatment with clopidogrel and aspirin followed by long-term therapy in patients undergoing percutaneous coronary intervention: the PCI-CURE study. Lancet 200I;358:527-33.

II. Steinhubl SR, Berger PB, Mann JT III, et al. Early and sustained dual oral antiplatelet therapy following percutaneous coronary intervention: a randomized controlled trial. JAMA 2002;288:24II-20.

I2. Smith SC Jr, Feldman TE, Hirshfeld JW Jr, et al. ACC/AHA/SCAI 2005 guideline update for percutaneous coronary intervention: a report of the American College of Cardiology/American Heart Association Task Force on Practice Guidelines (ACC/AHA/SCAI Writing Committee to Update 200I Guidelines for Percutaneous Coronary Intervention). Circulation 2006; II3:er66-286.

I3. Tamblyn R, Reid T, Mayo N, et al. Using medical services claims to assess injuries in the elderly: sensitivity of diagnostic and procedure codes for injury ascertainment. J Clin Epidemiol 2000;53:183-94.

I4. Tamblyn R, Lavoie G, Petrella L, et al. The use of prescription claims databases in pharmacoepidemiological research: the accuracy and comprehensiveness of the prescription claims database in Quebec. J Clin Epidemiol I995;48:999-Ioo9.

15. Rahme E, Marentette MA, Kong SX, et al. Use of NSAIDs, COX-2 inhibitors, and acetaminophen and associated coprescriptions of gastroprotective agents in an elderly population. Arthritis Rheum 2002;47:595-602.

I6. Rahme E, Pettitt D, Lelorier J. Determinants and sequelae associated with utilization of acetaminophen versus traditional nonsteroidal antiinflammatory drugs in an elderly population. Arthritis Rheum 2002;46:3046-54.

17. Catalan VS, Couture JA, Lelorier J. Predictors of persistence of use of the novel antidiabetic agent acarbose. Arch Intern Med 2001;16r:II06-I2.

I8. Garbe E, Lelorier J, Boivin JF, et al. Risk of ocular hypertension or open-angle glaucoma in elderly patients on oral glucocorticoids. Lancet I997;350:979-82.

I9. Government of Quebec. Manuel des médecins spécialistes. Québec: Bibliothèque nationale du Québec; 2005.

20. Von Korff M, Wagner EH, Saunders K. A chronic disease score from automated pharmacy data. J Clin Epidemiol I992;45:197-203.

2I. Aydemir U, Aydemir S, Dirschedl P. Analysis of time-dependent covariates in failure time data. Stat Med I999;I8:2123-34.

22. Dancourt V, Quantin C, Abrahamowicz M, et al. Modeling recurrence in colorectal cancer. JClin Epidemiol 2004;57:243-5I.

23. Giorgi R, Gouvernet J. Analysis of time-dependent covariates in a regressive relative survival model. Stat Med 2005;24:3863-70.

24. Spertus JA, Kettelkamp R, Vance C, et al. Prevalence, predictors, and outcomes of premature discontinuation of thienopyridine therapy after drug-eluting stent placement: results from the PREMIER registry. Circulation 2006;II3:2803-9.

25. Ackman ML, Graham MM, Hui C, et al. Effect of a prior authorization process on antiplatelet therapy and outcomes in patients prescribed clopidogrel following coronary stenting. Can J Cardiol 2006;22:1205-8.

26. Suissa S. Immortal time bias in observational studies of drug effects. Pharmacoepidemiol Drug Saf 2007;16:24I-9.

Correspondence to: Dr. Stéphane Rinfret, Pharmacoeconomics and Pharmacoepidemiology Unit, Interventional cardiology, Centre Hospitalier de l'Université de Montréal Research Centre, 3850 Saint-Urbain, Montréal QC H2W IT7; telephone 514-89o-80oo ext I4080; fax 5I4 4I2-7I74; s.rinfret@umontreal.ca 